\title{
VIEWPOINT
}

\section{Renal recovery}

\author{
Stuart L Goldstein ${ }^{1}$, Lakhmir Chawla ${ }^{2,3}$, Claudio Ronco ${ }^{4}$ and John A Kellum ${ }^{5,6^{*}}$
}

\begin{abstract}
Acute kidney injury (AKI) research in the past decade has mostly focused upon development of a standard AKI definition, validation of early novel biomarkers to predict AKI prior to serum creatinine rise and predict AKI severity, and assessment of aspects of renal replacement therapies and their impact on survival. Given the independent association between AKI and mortality in the acute phase, such focus makes imminent sense. More recently, the recognition that AKI is associated with subsequent development of chronic kidney disease and end-stage renal disease, with the attendant increase in mortality, has led to interest in the clinical epidemiology and the mechanistic understanding of renal recovery after an AKI episode in critically ill patients. We review the current knowledge surrounding renal recovery after an AKI episode, including renal replacement therapy initiation timing and modality impact, biomarker assessment and mechanistic targets to guide potential future clinical trials.
\end{abstract}

\section{Background}

The field of acute kidney injury (AKI) in the critically ill patient population has been subject to a significant research focus over the past decade. Hallmarks of this research progress include development and validation of standardized multidimensional AKI definitions [1,2], which help assessment of AKI outcomes, discovery of novel biomarkers to detect AKI development and predict AKI severity earlier [3], and prospective randomized trials enabling assessment of potentially modifiable aspects of AKI supportive care, namely the timing and intensity of renal replacement therapy delivery $[4,5]$. The realization that patients are dying from, and not just

\footnotetext{
* Correspondence: kellumja@ccm.upmc.edu

${ }^{5}$ Center for Critical Care Nephrology, CRISMA (Clinical Research, Investigation, and Systems Modeling of Acute IIIness) Center, Pittsburgh, PA 15621, USA ${ }^{6}$ Department of Critical Care Medicine, University of Pittsburgh School of Medicine, Pittsburgh, PA 15621, USA

Full list of author information is available at the end of the article
}

with, AKI [6] has driven the effort to alter the course of AKI. By reducing rates of 'kidney attack' [7,8], thereby preventing or at least mitigating AKI, patient mortality and morbidity should likewise be lessened. A natural extension of 'peri-AKI' epidemiological research would expand the focus to patients who survive an AKI episode, and a reassessment of the long-term consequences of AKI. The fact that episodes of AKI are associated with more rapid progression to chronic kidney disease (CKD) in adult patients is a relatively recent observation [9]; the 2009 United States Renal Data System Report revealed that adults with an AKI episode during hospitalization have an approximately 10-fold greater risk of progressing to end-stage renal disease than patients who did not experience AKI [10]. Similar observations were also reported around the same time for cardiac surgery patients [11]. The goals of this review on renal recovery after AKI are to 1) provide a state of the art description of our current understanding of the epidemiology of AKI survivors, 2) describe the evolution of novel biomarkers in the AKI to CKD field and 3) describe potential risk factors for renal recovery versus non-recovery in AKI survivors.

\section{Renal recovery: the definition}

\section{Serum creatinine-based definitions}

None of the advancements in AKI research would have occurred without development and validation of the first standardized multi-dimensional AKI definition, known as the RIFLE criteria (Risk, Injury, Failure, Loss, Endstage kidney disease) [1], and its subsequent recalibrations, pediatric RIFLE (pRIFLE) [12], the Acute Kidney Injury Network [2] and Kidney Disease Improving Global Outcomes (KDIGO) criteria [13]. Likewise, a standard definition of renal recovery is essential to provide an accurate account of post-AKI epidemiology. The Acute Dialysis Quality Initiative II work group provided the first such definition when they proposed the empiric RIFLE criteria, as the 'Loss' and 'End-stage kidney disease' strata ('L' and 'E') contained both estimated glomerular filtration rate (GFR) and time components in their metrics. Loss is defined as persistent complete loss of kidney 
function for greater than 4 weeks, and End-stage kidney disease is defined as complete loss of kidney function at 3 months after AKI development. The KDIGO AKI Workgroup proposed a refinement with the somewhat less severe concept of 'acute kidney disease' (AKD). AKD, defined as a GFR $<60 \mathrm{ml} /$ minute $/ 1.73 \mathrm{~m}^{2}$ or evidence of structural kidney damage for less than 3 months, provides an operationally integrated bridge between AKI and CKD. The AKD concept, which incorporates the concept of partial renal recovery, should be used to raise awareness and engender the necessary clinical mechanisms to follow AKI survivors for progression to CKD, which has been recently highlighted as a missed opportunity for adequate transitions of care [14].

Prospective AKI trials in the critically ill have mostly focused upon patients who receive acute renal replacement therapy (RRT), since they are at the highest risk for mortality and RRT is one of the few aspects of the AKI episode that is modifiable. A more temporally proximal definition of renal recovery was utilized in the Veterans Affairs/National Institutes of Health Acute Renal Failure Trial Network (ATN) trial; patients with a 6 hour creatinine clearance $>20 \mathrm{ml} /$ minute were trialed off RRT, whereas patients with a creatinine clearance $<12 \mathrm{ml} / \mathrm{mi}$ nute had RRT continued [4]. Thus, at the current time, the definition of renal recovery depends upon the time frame of interest, as depicted in Figure 1.

The report from the 2011 NIDDK Workshop on Clinical Trial Design [15] recently proposed a composite endpoint of death, dialysis provision and incomplete renal recovery at 28 or 60 days. This concept had already been used in the evaluation of plasma neutrophil gelatinase-associated lipocalin (NGAL) as a predictor of renal recovery defined by the composite of mortality, persistence of RIFLE-F or need for RRT [16] and was subsequently operationalized as Major Adverse Kidney Events at Day 30 in a study of novel AKI biomarker prediction of AKI and outcomes [17]. Future prospective interventional trials aimed at promoting renal recovery should consider incorporating at least one of these definitions as an outcome. An important consequence of these composite endpoints is that the issue of competing risk between persistent renal dysfunction, RRT and death is obviated by combining these outcomes into a single endpoint. In addition, they are perhaps more patientcentered since kidneys that recover in patients that die will be valued less by these patients.

GFR estimation reflects late functional changes, which are inherently delayed since the kidneys contain the innate ability to maintain function by hyperfiltration and compensatory hypertrophy of the remaining healthy nephrons, irrespective of the etiology for the kidney damage. This nephron adaptation allows for continued clearance of plasma solutes, so that serum creatinine increases only after about $50 \%$ of nephrons have been lost. Thus, it is important to note that even if creatininebased GFR returns to normal, there may be a potential loss of renal reserve, so that repeated episodes of AKI may unmask clinically detectable CKD.

There are alternatives to serum creatinine-based definitions of renal recovery, which include timed urine collections for creatinine clearance measurement, direct

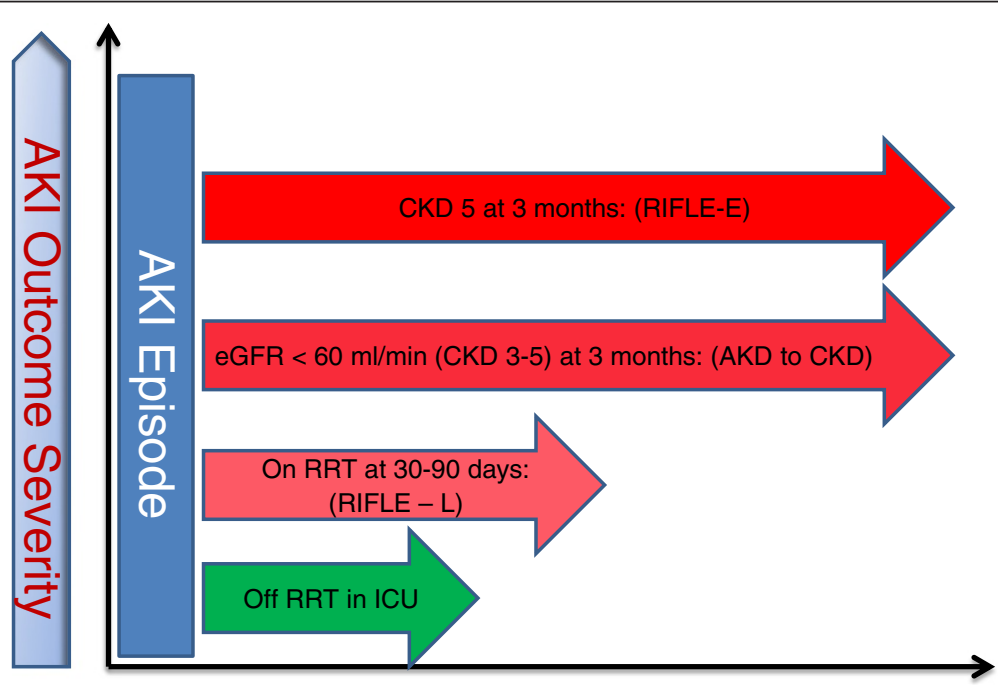

Figure 1 Time periods for renal recovery based on various study endpoints in the published literature. AKD, acute kidney disease [13]; AKI, acute kidney injury; CKD, chronic kidney disease; eGFR, estimated glomerular filtration rate; RIFLE-E, end-stage of of Risk, Injury, Failure, Loss, End-stage kidney disease criteria [1]; RIFLE-R, loss stage of Risk, Injury, Failure, Loss, End-stage kidney disease criteria; RRT, renal replacement therapy. 
GFR assessment by radionuclide clearance and GFR estimation using Cystatin $\mathrm{C}$, a molecule that has ideal properties of clearance by filtration with a serum concentration that is not dependent on muscle mass. Going forward, epidemiological research studies should employ these methods to reduce the issues with sole reliance on serum creatinine.

\section{Classic biomarker injury-based definitions}

While extensive research has been expended to identify novel biomarkers to identify acute kidney damage earlier and predict AKI severity [18,19], widespread outcomes studies of specific biomarkers for the early detection of progression from AKI to CKD do not exist. Thus, at present, in addition to the estimation of GFR noted above, measurement of proteinuria or microalbuminura, which are extrapolated from the diabetic nephropathy progression model, have been hallmarks of CKD assessment [20]. Proteinuria, albuminuria and microalbuminuria have been studied extensively in both adult and pediatric cross-sectional studies of AKI survivors [21-25]. Recent reports in adult populations have supported the use of proteinuria for prediction of adverse outcomes in CKD $[20,26,27]$. However, significant structural damage has typically already occurred before proteinuria is measureable, and kidney function decline has usually already commenced at the onset of microalbuminuria [28-30]. Furthermore, the predictive value of microalbuminuria has been questioned, since a large proportion of diabetic patients exhibit spontaneous resolution, and only a minority progress to overt proteinuria [31].

\section{Prediction of renal recovery}

One set of current tools for potentially predicting renal recovery is encompassed in clinical severity of illness (SOI) scores. While these may seem attractive options initially, it is important to remember that SOI scores are used to characterize and stratify adult and pediatric critical illness [32]. The initial SOI systems were developed to benchmark, or compare, critical care units against one another, to monitor resource use, evaluate therapies, and improve quality assessment. They were not intended to predict SOI in individual patients but, rather, to group patients together in strata of illness, which would allow group-wide mortality or SOI prediction. As an example, Uchino and colleagues [33] tested two general illness severity scores (Acute Physiology and Chronic Health Evaluation II and Sequential Organ Failure Assessment (SOFA)), and four AKI-specific severity scores in 1,742 patients as part of the BEST Kidney Study. None of these scoring systems tested had a high level of discrimination or calibration to predict outcome for AKI patients. If systems do not perform well to predict AKI- associated mortality, it is no wonder that prediction of renal recovery has remained elusive as well [34]. Although factors such as advanced age, male gender, presence of sepsis/septic shock, hypotension, respiratory failure, use of mechanical ventilation, presence of oliguria, and high serum bilirubin, low serum creatinine, and using vasoactive substances are risk factors for AKI [35], we know far less about the clinical determinants of renal recovery. In a small study, a subset $(n=76)$ of the ATN study cohort [4], Srisawat and colleagues found that age and underlying chronic disease predicted nonrecovery of renal function (area under the curve (AUC) 0.74) following provision of RRT for AKI [16]. Determinants of renal recovery may be influenced by etiology of AKI. The same authors studied recovery following severe AKI (RIFLE-F) in patients with community-acquired pneumonia and found that a model composed of age, creatinine on the first day of RIFLE-F, pneumonia severity index on admission, and maximum non-renal SOFA score yielded an AUC of 0.78 [36].

Some recent work has demonstrated promise for clinical prediction for renal recovery with more specific markers. A systematic review of patients with hemolytic uremic syndrome revealed that renal replacement therapy provision and central nervous system involvement increased risk for end-stage renal disease [37], although rates of renal recovery were not directly addressed. A recent assessment of AKI to stage 4 CKD progression in the US Veterans population developed and then validated three models to predict CKD risk, with increasing AKI severity by RIFLE score and in-hospital hypoalbuminemia providing the strongest prediction [38]. Of note, each increase in RIFLE score was associated with an adjusted odds ratio of 4.43 for development of stage 4 CKD, which was higher than any other covariate except the need for RRT. Although these models require validation in other cohorts and should be tested longitudinally in a systematic assessment of patients at risk for AKI, they provide some clues as to which patients should be targeted for close follow-up and potentially therapeutic trials to slow CKD progression.

Although oliguria (urine output less than $400 \mathrm{ml} /$ day) is a common event in the ICU and urine flow is one of the diagnostic and staging criteria for AKI, only a few studies have focused on the role of urine output as a prognostic renal biomarker. Oliguric patients without change in serum creatinine concentrations demonstrated increased mortality rates and dialysis requirements similar to patients with serum creatinine change-based AKI [39]. A post hoc analysis from the BEST kidney study revealed that the urine output area under the receiver operating characteristic curve for successful discontinuation of continuous RRT (CRRT) was 0.85 , although it fell to 0.67 when diuretics were used. Urine output 
cutoffs of $436 \mathrm{ml} /$ day and 2,330 $\mathrm{ml} /$ day for patients without and with diuretics, respectively, had the highest accuracy [40].

Recently, some studies have begun to assess the ability of novel biomarkers to predict renal recovery and/or progression to CKD. NGAL has been extensively studied in the field of AKI [41]. In the late phase of AKI, NGAL is believed to play a role as a growth and differentiation factor for restoring tubular epithelial function with the assistance of siderophore-iron complexes. However, most previous studies have tested plasma/urine NGAL as a marker for early diagnosis of AKI; only a few studies have examined plasma/urine NGAL as a prognosticate marker of clinical outcome, mostly with mortality and hospital length of stay as endpoints. In fact, a systematic review demonstrated similar mortality rates and length of stay for patients with 'NGAL-positive: creatininenegative' AKI versus 'NGAL-negative: creatininepositive' AKI [42].

Two studies (also mentioned above) have assessed NGAL as a predictor of renal recovery $[16,36]$. Plasma NGAL was assessed in patients with communityacquired pneumonia on the first day they experienced severe AKI (defined as RIFLE-F), and recovery was defined as being alive and neither requiring RRT during hospitalization nor having a persistent RIFLE-F classification at hospital discharge [36]. The investigators found that elevated plasma NGAL levels were associated with renal non-recovery with a $17 \%$ increase in predicting renal non-recovery. The second study, the Biological Markers of Recovery for the Kidney study [16], was conducted as an ancillary to the ATN study [4]. Urine samples were collected on days 1,7 , and 14 from 76 patients who developed AKI and received RRT in the ICU. For predicting recovery, decreasing urinary NGAL and urinary hepatocyte growth factor in the first 14 days was associated with greater odds of renal recovery.

Interestingly, animal models of AKI-to-CKD transition identify NGAL, as well as another novel AKI biomarker, Kidney injury molecule-1 (KIM-1), as two of the most upregulated genes and proteins in the kidney, revealing a possible role for these proteins as biomarkers [43]. Furthermore, studies on urinary NGAL and KIM-1 in other renal diseases demonstrate higher NGAL concentrations are associated with more rapid progression of CKD [44-49]. Coupling the animal data with the human data noted provides evidence that novel biomarkers can serve as early markers of ongoing renal injury, even in the setting of AKI. The clinical impact is potentially great in the setting of AKI, for even if a patient is undergoing dialysis, therapies directed at mitigating ongoing injury may have a role in AKI treatment and CKD prevention.

\section{Promoting renal recovery}

\section{Mechanisms of recovery}

The kidney has a tremendous capacity for repair following different types of AKI. Interestingly, regeneration and repair mechanisms lead to the expression of many different developmental signaling pathways [50]. Proximal tubular epithelial cells are particularly susceptible to AKI as they are positioned closest to the glomeruli (and are thus first to 'see' various endogenous and exogenous toxins) [51] as well as having the highest metabolic rate (and are thus susceptible to ischemia and metabolic toxins). Once injured, tubular epithelial cells can re-differentiate after an initial phase of dedifferentiation and proliferation, thus replacing cells that are lost to necrosis, apoptosis, or simply shedding from the basement membrane during injury [52]. This 'healthy repair process' can go awry at various stages, leading to fibrosis and CKD. Various mechanisms have been implicated in controlling the repair process [53], many of which may represent drug targets. Recently, Notch signaling, a cell-cell communication mechanism that regulates development, tissue homeostasis and repair, has been identified to play a potential role in repair and regeneration after AKI [54]. Generally absent in the mature kidney, Notch is reactivated after AKI, and could be responsible for cellular differentiation, proliferation and repair [55]. This notion is supported by studies from various laboratories that independently observed a linkage between increased expression of Notch2 and its target Hes1 and increased proliferation of renal tubular epithelial cells in the setting of various insults [56-58].

\section{Therapies}

While a number of medications have been studied to prevent AKI development and severity, including diuretics, adenosine A1 receptor antagonist and dopamine receptor alpha1-specific agonists, the results have been nearly uniformly negative [59-61], although fenoldopam has been shown to improve urine output and NGAL elevation in children after cardiac surgery in a pilot study $[62,63]$. Thus, it logically follows that these agents may not be helpful to promote renal recovery. New therapies aimed more specifically at mechanisms of renal fibrosis and maladaptive repair are under development, some with promising pre-clinical results.

Two aspects of RRT provision have recently been assessed for their potential impact on renal recovery: fluid overload at the time of RRT initiation and RRT modality. Each of these factors is important, since they represent potentially modifiable treatment decisions available today to improve outcomes. The association between increasing degrees of fluid overload at RRT initiation as well as the negative impact of fluid overload in critically ill patients with and without AKI has been well 
documented in the pediatric and adult critical care literature. Multiple multicenter studies demonstrate increased mortality in patients with greater than 10 to $20 \%$ ICU fluid accumulation at CRRT initiation [64-66]. A single center study demonstrated that initiation of RRT at less than $10 \%$ fluid overload was associated with improved renal recovery, with each $1 \%$ of fluid overload carrying a $3 \%$ reduction in renal recovery rates [67]. The potential explanation for this association posits that fluid overload increases the risk of intra-abdominal compartment syndrome and increases renal venous pressure, leading to renal interstitial edema with resultant decreased glomerular filtration, distorted tissue architecture, and impaired tissue perfusion.

The two recent, large, well conducted, randomized, multicenter trials, ATN [4] and RENAL [5], which did not demonstrate a benefit of higher RRT intensity on survival or renal recovery, have provided high-quality data to assess the impact of RRT modality on renal recovery, since the two studies had very different rates of renal recovery. Overall, the cohorts were closely matched; however, recovery of renal function by day 28 was substantially better in RENAL versus ATN (87\% versus $55 \%$ ).

What differences between the two studies could account for this difference in renal recovery? Although the chronological time to start of treatment was shorter in RENAL compared to ATN (2.1 versus 6.7 days), the BUN concentration at the start of therapy (another surrogate for timing) was nearly identical. Another difference between the two trials that could have accounted for the differences in outcomes was the exclusive use of CRRT as the initial mode of RRT in the RENAL trial compared to a strategy that allocated patients to CRRT only if they were hemodynamically unstable (cardiovascular SOFA score $>2$ ) in the ATN trial, while more stable patients received intermittent hemodialysis.

A very recent meta-analysis of RRT modality and renal recovery lends significant credence to the proposition that CRRT is associated with improved renal recovery compared to intermittent RRT (IRRT) [68]. Ultimately, 23 total studies (randomized controlled $\mathrm{n}=7$, observational $\mathrm{n}=16$ ), comprising 3,977 AKI survivors, fulfilled criteria for the comparison of CRRT to IRRT. Pooled averages from the studies demonstrated that patients receiving IRRT initially were generally less severely ill, with lower rates of mechanical ventilation, vasopressor administration and CKD. The overall relative risk (RR) from all studies for dialysis dependence was higher for IRRT patients (RR 1.73, 95\% confidence interval (CI) 1.35 to 2.20). However, this association was not observed in the pooled average of randomized controlled trials (RR 1.15, 95\% CI 0.78 to 1.68 ), and only held true in the pooled averages for the observational trials (RR 1.99,
95\% CI 1.53 to 2.59). The authors note that the randomized controlled trials only included small studies (combined patient total of 472 AKI survivors) and enrolled less severely ill patients. Furthermore, most randomized controlled trials have only included patients who could receive either modality, excluding those deemed too unstable for standard IRRT.

\section{Conclusion}

Recovery of renal function following an episode of AKI is far from certain and a growing body of evidence suggests that progression of underlying CKD or even development of de novo CKD may occur following an episode of AKI. Patients who fail to recover will have a significantly shorter life-span and succumb to a number of morbidities. The underlying cellular and physiologic mechanisms that drive outcomes after AKI are poorly characterized. Epidemiologic evidence strongly suggests that advanced age is the most significant risk factor for non-recovery of renal function but this may merely reflect a diminished renal functional reserve in this population. Since there is a potential independent risk conferred by multiple AKI episodes on CKD progression [9], the clinical focus at present must continue to be on avoiding subsequent AKI episodes in the critically ill.

\section{Abbreviations}

AKD: Acute kidney disease; AKI: Acute kidney injury; ATN: Acute renal failure trial network; AUC: Area under the curve; Cl: Confidence interval; CKD: Chronic kidney disease; CRRT: Continuous renal replacement therapy; GFR: Glomerular filtration rate; IRRT: Intermittent renal replacement therapy; KDIGO: Kidney disease improving global outcomes; KIM-1: Kidney injury molecule-1; NGAL: Neutrophil gelatinase-associated lipocalin; RIFLE: Risk, injury, failure, loss, end-stage kidney disease; RR: Relative risk; RRT: Renal replacement therapy; SOFA: Sequential organ failure assessment; SOl: Severity of illness.

\section{Competing interests}

The authors declare that they have no competing interests.

\section{Author details}

${ }^{1}$ Center for Acute Care Nephrology, Cincinnati Children's Hospital Medical Center, Cincinnati, $\mathrm{OH} 45229$, USA. ${ }^{2}$ Department of Anesthesiology and Critical Care Medicine, George Washington University Medical Center, Washington DC Division of Renal Diseases and Hypertension, Washington, DC 20037, USA. ${ }^{3}$ Department of Medicine, George Washington University Medical Center, Washington, DC 20037, USA. Department of Nephrology, Dialysis and Transplantation, International Renal Research Institute, San Bortolo Hospital, Vicenza 36100, Italy. ${ }^{5}$ Center for Critical Care Nephrology, CRISMA (Clinical Research, Investigation, and Systems Modeling of Acute Illness) Center, Pittsburgh, PA 15621, USA. ${ }^{6}$ Department of Critical Care Medicine, University of Pittsburgh School of Medicine, Pittsburgh, PA 15621, USA.

\section{Published: 06 Jan 2014}

\section{References}

1. Bellomo R, Ronco C, Kellum JA, Mehta RL, Palevsky P: Acute renal failure definition, outcome measures, animal models, fluid therapy and information technology needs: the Second International Consensus Conference of the Acute Dialysis Quality Initiative (ADQI) Group. Crit Care 2004, 8: R204-R212. 
2. Mehta RL, Kellum JA, Shah SV, Molitoris BA, Ronco C, Warnock DG, Levin A: Acute Kidney Injury Network: report of an initiative to improve outcomes in acute kidney injury. Crit Care 2007, 11:R31.

3. Devarajan P: Emerging urinary biomarkers in the diagnosis of acute kidney injury. Expert Opin Med Diagn 2008, 2:387-398.

4. VA/NIH Acute Renal Failure Trial Network, Palevsky PM, Zhang JH, O'Connor TZ, Chertow GM, Crowley ST, Choudhury D, Finkel K, Kellum JA, Paganini E, Schein RM, Smith MW, Swanson KM, Thompson BT, Vijayan A, Watnick S, Star RA, Peduzzi P: Intensity of renal support in critically ill patients with acute kidney injury. N Engl J Med 2008, 359:7-20.

5. RENAL Replacement Therapy Study Investigators, Bellomo R, Cass A, Cole L, Finfer S, Gallagher M, Lo S, McArthur C, McGuinness S, Myburgh J, Norton R, Scheinkestel C, Su S: Intensity of continuous renal-replacement therapy in critically ill patients. N Engl J Med 2009, 361:1627-1638.

6. Kellum JA, Angus DC: Patients are dying of acute renal failure. Crit Care Med 2002, 30:2156-2157.

7. Kellum JA, Bellomo R, Ronco C: Kidney attack. JAMA 2012, 307:2265-2266.

8. Ronco C: Kidney attack: overdiagnosis of acute kidney injury or comprehensive definition of acute kidney syndromes? Blood Purif 2013, 36:65-68.

9. Thakar CV, Christianson A, Himmelfarb J, Leonard AC: Acute kidney injury episodes and chronic kidney disease risk in diabetes mellitus. Clin J Am Soc Nephrol 2011, 6:2567-2572.

10. Collins AJ, Foley RN, Herzog C, Chavers B, Gilbertson D, Ishani A, Kasiske B, Liu J, Mau LW, McBean M, Murray A, St Peter W, Guo H, Li Q, Li S, Li S, Peng Y, Qiu Y, Roberts T, Skeans M, Snyder J, Solid C, Wang C, Weinhandl E, Zaun D, Arko C, Chen SC, Dalleska F, Daniels F, Dunning S, et al: United States Renal Data System 2008 Annual Data Report. Am J Kidney Dis 2009, 53:S1-S374.

11. Hobson CE, Yavas S, Segal MS, Schold JD, Tribble CG, Layon AJ, Bihorac A: Acute kidney injury is associated with increased long-term mortality after cardiothoracic surgery. Circulation 2009, 119:2444-2453.

12. Akcan-Arikan A, Zappitelli M, Loftis LL, Washburn KK, Jefferson LS, Goldstein SL: Modified RIFLE criteria in critically ill children with acute kidney injury. Kidney Int 2007, 71:1028-1035.

13. Kidney Disease: Improving Global Outcomes (KDIGO) Acute Kidney Injury Work Group - KDIGO Clinical Practice Guideline for Acute Kidney Injury. Kidney Int 2012, Suppl:1-138.

14. Goldstein SL, Jaber BL, Faubel S, Chawla LS: Acute Kidney Injury Advisory Group of American Society of Nephrology: AKI transition of care: a potential opportunity to detect and prevent CKD. Clin J Am Soc Nephrol 2013, 8:476-483.

15. Palevsky PM, Molitoris BA, Okusa MD, Levin A, Waikar SS, Wald R, Chertow GM, Murray PT, Parikh CR, Shaw AD, Go AS, Faubel SG, Kellum JA, Chinchilli VM, Liu KD, Cheung AK, Weisbord SD, Chawla LS, Kaufman JS, Devarajan P, Toto RM, Hsu CY, Greene T, Mehta RL, Stokes JB, Thompson AM, Thompson BT, Westenfelder CS, Tumlin JA, Warnock DG, et al: Design of clinical trials in acute kidney injury: report from an NIDDK workshop on trial methodology. Clin J Am Soc Nephrol 2012, 7:844-850.

16. Srisawat $N$, Wen $X$, Lee $M$, Kong L, Elder M, Carter M, Unruh M, Finkel K, Vijayan A, Ramkumar M, Paganini E, Singbartl K, Palevsky PM, Kellum JA: Urinary biomarkers and renal recovery in critically ill patients with renal support. Clin J Am Soc Nephrol 2011, 6:1815-1823.

17. Kashani K, Al-Khafaji A, Ardiles T, Artigas A, Bagshaw SM, Bell M, Bihorac A, Birkhahn R, Cely CM, Chawla LS, Davison DL, Feldkamp T, Forni LG, Gong MN, Gunnerson KJ, Haase M, Hackett J, Honore PM, Hoste EA, JoannesBoyau O, Joannidis M, Kim P, Koyner JL, Laskowitz DT, Lissauer ME, Marx G, McCullough PA, Mullaney S, Ostermann M, Rimmelé T, et al: Discovery and validation of cell cycle arrest biomarkers in human acute kidney injury. Crit Care 2013, 17:R25.

18. Coca SG, Yalavarthy R, Concato J, Parikh CR: Biomarkers for the diagnosis and risk stratification of acute kidney injury: a systematic review. Kidney Int 2008, 73:1008-1016.

19. Waikar SS, Bonventre JV: Biomarkers for the diagnosis of acute kidney injury. Nephron Clin Pract 2008, 109:C192-c197.

20. Levey AS, Cattran D, Friedman A, Miller WG, Sedor J, Tuttle K, Kasiske B, Hostetter T: Proteinuria as a surrogate outcome in CKD: report of a scientific workshop sponsored by the National Kidney Foundation and the US Food and Drug Administration. Am J Kidney Dis 2009, 54:205-226.

21. Askenazi DJ, Feig DI, Graham NM, Hui-Stickle S, Goldstein SL: 3-5 year longitudinal follow-up of pediatric patients after acute renal failure. Kidney Int 2006, 69:184-189.
22. Mammen C, Al Abbas A, Skippen P, Nadel H, Levine D, Collet JP, Matsell DG: Long-term risk of CKD in children surviving episodes of acute kidney injury in the intensive care unit: a prospective cohort study. Am J Kidney Dis 2012, 59:523-530.

23. Garg AX, Salvadori M, Okell JM, Thiessen-Philbrook HR, Suri RS, Filler G, Moist L, Matsell D, Clark WF: Albuminuria and estimated GFR 5 years after Escherichia coli 0157 hemolytic uremic syndrome: an update. Am J Kidney Dis 2008, 51:435-444

24. Coca SG, Singanamala S, Parikh CR: Chronic kidney disease after acute kidney injury: a systematic review and meta-analysis. Kidney Int 2012, 81:442-448.

25. Goldstein SL, Devarajan P: Progression from acute kidney injury to chronic kidney disease: a pediatric perspective. Adv Chronic Kidney Dis 2008, 15:278-283.

26. Hemmelgarn BR, Manns BJ, Lloyd A, James MT, Klarenbach S, Quinn RR, Wiebe N, Tonelli M: Relation between kidney function, proteinuria, and adverse outcomes. JAMA 2010, 303:423-429.

27. Hallan SI, Ritz E, Lydersen S, Romundstad S, Kvenild K, Orth SR: Combining GFR and albuminuria to classify CKD improves prediction of ESRD. J Am Soc Nephrol 2009, 20:1069-1077.

28. Chaudhary K, Phadke G, Nistala R, Weidmeyer CE, McFarlane SI, WhaleyConnell A: The emerging role of biomarkers in diabetic and hypertensive chronic kidney disease. Curr Diab Rep 2010, 10:37-42.

29. Merchant ML, Perkins BA, Boratyn GM, Ficociello LH, Wilkey DW, Barati MT, Bertram CC, Page GP, Rovin BH, Warram JH, Krolewski AS, Klein JB: Urinary peptidome may predict renal function decline in type 1 diabetes and microalbuminuria. J Am Soc Nephrol 2009, 20:2065-2074.

30. Perkins BA, Ficociello LH, Ostrander BE, Silva KH, Weinberg J, Warram JH, Krolewski AS: Microalbuminuria and the risk for early progressive renal function decline in type 1 diabetes. J Am Soc Nephrol 2007, 18:1353-1361.

31. Perkins BA, Ficociello LH, Silva KH, Finkelstein DM, Warram JH, Krolewski AS: Regression of microalbuminuria in type 1 diabetes. N Engl J Med 2003, 348:2285-2293.

32. Vincent $J$, Moreno R: Clinical review: scoring systems in the critically ill. Crit Care 2010, 14:207.

33. Uchino S, Bellomo R, Morimatsu H, Morgera S, Schetz M, Tan I, Bouman C, Macedo E, Gibney N, Tolwani A, Doig GS, Oudemans Van Straaten H, Ronco C, Kellum JA, Beginning and Ending Supportive Therapy for the Kidney (B.E. S.T. Kidney) Investigators: External validation of severity scoring systems for acute renal failure using a multinational database. Crit Care Med 2005, 33:1961-1967.

34. Basu RK, Chawla LS, Wheeler DS, Goldstein SL: Renal angina: an emerging paradigm to identify children at risk for acute kidney injury. Pediatr Nephrol 2012, 27:1067-1078.

35. Goldstein SL, Chawla LS: Renal angina. Clin J Am Soc Nephrol 2010, 5:943949.

36. Srisawat N, Murugan R, Lee $M$, Kong L, Carter M, Angus DC, Kellum JA Genetic Inflammatory Markers of Sepsis Study I: Plasma neutrophil gelatinase-associated lipocalin predicts recovery from acute kidney injury following community-acquired pneumonia. Kidney Int 2011, 80:545552.

37. Garg AX, Suri RS, Barrowman N, Rehman F, Matsell D, Rosas-Arellano MP, Salvadori M, Haynes RB, Clark WF: Long-term renal prognosis of diarrheaassociated hemolytic uremic syndrome: a systematic review, metaanalysis, and meta-regression. JAMA 2003, 290:1360-1370.

38. Chawla LS, Amdur RL, Amodeo S, Kimmel PL, Palant CE: The severity of acute kidney injury predicts progression to chronic kidney disease. Kidney Int 2011, 79:1361-1369.

39. Macedo E, Malhotra R, Bouchard J, Wynn SK, Mehta RL: Oliguria is an early predictor of higher mortality in critically ill patients. Kidney Int 2011, 80:760-767.

40. Uchino S, Bellomo R, Morimatsu H, Morgera S, Schetz M, Tan I, Bouman C, Macedo E, Gibney N, Tolwani A, Straaten HO, Ronco C, Kellum JA: Discontinuation of continuous renal replacement therapy: a post hoc analysis of a prospective multicenter observational study. Crit Care Med 2009, 37:2576-2582.

41. Devarajan P: Review: Neutrophil gelatinase-associated lipocalin: a troponin-like biomarker for human acute kidney injury. Nephrology (Carlton) 2010, 15:419-428.

42. Haase M, Devarajan P, Haase-Fielitz A, Bellomo R, Cruz DN, Wagener G, Krawczeski CD, Koyner JL, Murray P, Zappitelli M, Goldstein SL, Makris K, 
Ronco C, Martensson J, Martling CR, Venge P, Siew E, Ware LB, Ikizler TA, Mertens PR: The outcome of neutrophil gelatinase-associated lipocalinpositive subclinical acute kidney injury: a multicenter pooled analysis of prospective studies. J Am Coll Cardiol 2011, 57:1752-1761.

43. Ko GJ, Grigoryev DN, Linfert D, Jang HR, Watkins T, Cheadle C, Racusen L, Rabb H: Transcriptional analysis of kidneys during repair from AKI reveals possible roles for NGAL and KIM-1 as biomarkers of AKI-to-CKD transition. Am J Physiol Renal Physiol 2010, 298:F1472-F1483.

44. Bolignano D, Coppolino G, Lacquaniti A, Nicocia G, Buemi M: Pathological and prognostic value of urinary neutrophil gelatinase-associated lipocalin in macroproteinuric patients with worsening renal function. Kidney Blood Press Res 2008, 31:274-279.

45. Bolignano D, Lacquaniti A, Coppolino G, Donato V, Campo S, Fazio MR, Nicocia G, Buemi M: Neutrophil gelatinase-associated lipocalin (NGAL) and progression of chronic kidney disease. Clin J Am Soc Nephrol 2009, 4:337-344.

46. Yang YH, He XJ, Chen SR, Wang L, Li EM, Xu LY: Changes of serum and urine neutrophil gelatinase-associated lipocalin in type- 2 diabetic patients with nephropathy: one year observational follow-up study. Endocrine 2009, 36:45-51.

47. Waanders F, Vaidya VS, van Goor H, Leuvenink H, Damman K, Hamming I, Bonventre JV, Vogt L, Navis G: Effect of renin-angiotensin-aldosterone system inhibition, dietary sodium restriction, and/or diuretics on urinary kidney injury molecule 1 excretion in nondiabetic proteinuric kidney disease: a post hoc analysis of a randomized controlled trial. Am J Kidney Dis 2009, 53:16-25.

48. van Timmeren MM, van den Heuvel MC, Bailly V, Bakker SJ, van Goor H, Stegeman CA: Tubular kidney injury molecule-1 (KIM-1) in human renal disease. J Pathol 2007, 212:209-217.

49. van Timmeren MM, Vaidya VS, van Ree RM, Oterdoom LH, de Vries AP, Gans $\mathrm{RO}$, van Goor H, Stegeman CA, Bonventre JV, Bakker SJ: High urinary excretion of kidney injury molecule- 1 is an independent predictor of graft loss in renal transplant recipients. Transplantation 2007, 84:16251630.

50. Lazzeri E, Mazzinghi B, Romagnani P: Regeneration and the kidney. Curr Opin Nephrol Hypertens 2010, 19:248-253.

51. Wen X, Murugan R, Peng Z, Kellum JA: Pathophysiology of acute kidney injury: a new perspective. Contrib Nephrol 2010, 165:39-45.

52. Venkatachalam MA, Griffin KA, Lan R, Geng H, Saikumar P, Bidani AK: Acute kidney injury: a springboard for progression in chronic kidney disease. Am J Physiol Renal Physiol 2010, 298:F1078-F1094.

53. Singbartl K, Kellum JA: AKI in the ICU: definition, epidemiology, risk stratification, and outcomes. Kidney Int 2012, 81:819-825.

54. Sirin Y, Susztak K: Notch in the kidney: development and disease. J Pathol 2012, 226:394-403.

55. McCright B: Notch signaling in kidney development. Curr Opin Nephrol Hypertens 2003, 12:5-10

56. Kobayashi T, Terada Y, Kuwana H, Tanaka H, Okado T, Kuwahara M, Tohda S, Sakano S, Sasaki S: Expression and function of the Delta-1/Notch-2/Hes-1 pathway during experimental acute kidney injury. Kidney Int 2008 73:1240-1250

57. Gupta S, Li S, Abedin MJ, Wang L, Schneider E, Najafian B, Rosenberg M: Effect of Notch activation on the regenerative response to acute renal failure. Am J Physiol Renal Physiol 2010, 298:F209-F215.

58. Bielesz B, Sirin Y, Si H, Niranjan T, Gruenwald A, Ahn S, Kato H, Pullman J, Gessler M, Haase VH, Susztak K: Epithelial Notch signaling regulates interstitial fibrosis development in the kidneys of mice and humans. $J$ Clin Invest 2010, 120:4040-4054

59. Bagshaw SM, Bellomo R, Kellum JA: Oliguria, volume overload, and loop diuretics. Crit Care Med 2008, 36:S172-S178.

60. Tumlin JA, Finkel KW, Murray PT, Samuels J, Cotsonis G, Shaw AD: Fenoldopam mesylate in early acute tubular necrosis: a randomized, double-blind, placebo-controlled clinical trial. Am J Kidney Dis 2005, 46:26-34.

61. Voors AA, Dittrich HC, Massie BM, DeLucca P, Mansoor GA, Metra M, Cotter G, Weatherley BD, Ponikowski P, Teerlink JR, Cleland JG, O'Connor CM, Givertz MM: Effects of the adenosine A1 receptor antagonist rolofylline on renal function in patients with acute heart failure and renal dysfunction: results from PROTECT (Placebo-Controlled Randomized Study of the Selective Adenosine A1 Receptor Antagonist Rolofylline for Patients Hospitalized with Acute Decompensated Heart Failure and
Volume Overload to Assess Treatment Effect on Congestion and Renal Function). J Am Coll Cardiol 2011, 57:1899-1907.

62. Ricci Z, Luciano R, Favia I, Garisto C, Muraca M, Morelli S, Di Chara L, Cogo P, Pcardo S: High-dose fenoldopam reduces post operative neutrophil gelatinase associated lipocaline and cystatin $\mathrm{C}$ levels in pediatric cardiac surgery. Crit Care 2011, 15:R160.

63. Moffett BS, Mott AR, Nelson DP, Goldstein SL, Jefferies JL: Renal effects of fenoldopam in critically ill pediatric patients: a retrospective review. Pediatr Crit Care Med 2008, 9:403-406.

64. Sutherland SM, Zappitelli M, Alexander SR, Chua AN, Brophy PD, Bunchman TE, Hackbarth R, Somers MJ, Baum M, Symons JM, Flores FX, Benfield M, Askenazi D, Chand D, Fortenberry JD, Mahan JD, McBryde K, Blowey D, Goldstein SL: Fluid overload and mortality in children receiving continuous renal replacement therapy: the prospective pediatric continuous renal replacement therapy registry. Am J Kidney Dis 2010, 55:316-325.

65. Bouchard J, Soroko SB, Chertow GM, Himmelfarb J, Ikizler TA, Paganini EP, Mehta RL: Fluid accumulation, survival and recovery of kidney function in critically ill patients with acute kidney injury. Kidney Int 2009, 76:422427.

66. Goldstein SL, Somers MJ, Baum MA, Symons JM, Brophy PD, Blowey D, Bunchman TE, Baker C, Mottes T, McAfee N, Barnett J, Morrison G, Rogers K, Fortenberry JD: Pediatric patients with multi-organ dysfunction syndrome receiving continuous renal replacement therapy. Kidney Int 2005, 67:653658.

67. Heung M, Wolfgram DF, Kommareddi M, Hu Y, Song PX, Ojo AO: Fluid overload at initiation of renal replacement therapy is associated with lack of renal recovery in patients with acute kidney injury. Nephrol Dial Transplant 2012, 27:956-961.

68. Schneider AG, Bellomo R, Bagshaw SM, Glassford NJ, Lo S, Jun M, Cass A, Gallagher M: Choice of renal replacement therapy modality and dialysis dependence after acute kidney injury: a systematic review and metaanalysis. Intensive Care Med 2013, 39:987-997.

\section{$10.1186 / \mathrm{cc} 13180$}

Cite this article as: Goldstein et al:: Renal recovery. Critical Care

2014, 18:301 